\title{
Development of a motorcycle frame as a problem-based learning experience in design courses for Mechanical Engineering students
}

\author{
Cristian Iorga, P.Eng., Ph.D. \\ Post-doctoral fellow \\ Cristian.Iorga@USherbrooke.ca
}

\author{
Alain Desrochers, P.Eng. Ph.D. \\ Professor \\ Alain.Desrochers@USherbrooke.ca
}

\author{
Department of Mechanical Engineering, \\ Faculty of Engineering, Université de Sherbrooke \\ 2500 Boul. de 1'Université, J1K 2R1 \\ Sherbrooke (QC), Canada
}

\section{Abstract:}

The paradox that exists between the necessity of testing physical prototypes to achieve as much design criteria as possible and the desire to minimize the number of iterations at the experimental validation stage to manage development time and cost, has led the authors to develop a detailed design methodology that guides the engineers and designers through the main activities of the product development process (PDP).

The numerical validation activities and the iterations performed at the detailed design phase of the PDP have become key in achieving a product that meets the client needs from a pricelperformance/reliability perspective. However, before starting the fabrication of a physical prototype, the multidisciplinary team must understand the issues linked to the material behavior under critical conditions of use and in relation with the range of selected processes.

In previous papers, a generic methodology that takes into account several design criteria was presented. This methodology was applied to the recreational product industry with the aim of reducing the weight of a roadster frame while controlling its production cost. Specific to vehicle, fatigue and rigidity are amongst the structural criteria that are central to the safety of the user and the handling of the vehicle.

The objectives of this paper are thus to outline the advantages of this methodology, show how it could be applied to the structural sub-systems and components of a vehicle, and how it could be integrated in an undergraduate project, taking into account all the design criteria established up-stream in the PDP.

As this approach has already been validated in the recreational product industry, it will allow students to converge toward creative, effective but realistic solutions while providing a comprehensive feedback on the client needs.

\section{INTRODUCTION}

Due to lack of experience in engineering design, students involved in both undergraduate and postgraduate projects often find it difficult to reach all product requirements related to the real-world context, leading to the development of designs which are not totally in line with the client needs and consequently, are not marketable.

Teaching students through as much case-studies as possible during the engineering design courses thus becomes key in achieving competencies in several branches of engineering design: materials, structural statics, structural dynamics, numerical and experimental analysis, thermodynamics, economics, etc. [1 and 2]

\section{MECHANICAL DESIGN COURSES AT UdeS}

The teaching philosophy at Université de Sherbrooke is based on the concept of developing competencies, rather than on acquiring knowledge.

This philosophy allows students to often put themselves in real world contexts and manage complex situations inspired from professional engineering practice [3].

\subsection{ENGINEERING DESIGN COURSE AT UdeS: DESIGN METHODOLOGIES (IMC156)}

At the fifth session in Mechanical Engineering, students are confronted with their first project in which they have to develop a product which has to respect several design criteria, while having the generic guidelines needed to 
reach the objectives of the preliminary stage of the design process [3].

This course represents a preamble for the undergraduate capstone project and helps students adapt their knowhow to the main issues that are encountered in industry: cost, security, schedule, and quality.

During this course students deal with several theoretical tools to identify and analyze the client's needs, the product's functions, and product's specifications as well as the emergence and the convergence of the concepts [3 and 4].

The workshops provided in parallel with the theoretical lessons allow students to properly apply various design tools and to understand the importance of each step of the product design process.

Foremost, several teams of 5 or 6 students are formed and mini-projects are presented. The teams decide which theme is most appropriate for them.

In the following lines, there are some examples of products proposed to be developed: 1) Bear Trap, 2) Wrench, 3) Stool, 4) Mouse Trap, 5) Glass Scraper, 6) Corkscrew, etc.

Figure 1 illustrates a morphological matrix with several concepts, performed by students as the result of a brain storming step for the undergraduate project in which an electric motorcycle will be developed.

Each deliverable of the mini-projects has to be evaluated before the beginning of the next step. The students will also evaluate themselves, this approach making them aware of their responsibility and giving them an experience of group project work and design [3].

\begin{tabular}{|c|c|c|c|c|}
\hline & $\begin{array}{c}\text { YASA Motors } \\
(2 \mathrm{X})\end{array}$ & $\begin{array}{c}\text { ENSTROJ } \\
(2 \mathrm{X})\end{array}$ & $\begin{array}{c}\text { EVO electric } \\
(2 \mathrm{X})\end{array}$ & $\begin{array}{c}\text { LMC } \\
(2 \mathrm{X})\end{array}$ \\
\hline $\begin{array}{c}\text { Masse } \\
\text { (kg) }\end{array}$ & 48 & 24 & 66 & 22 \\
\hline $\begin{array}{c}\text { Puissanc } \\
\text { e } \\
\text { minimale }\end{array}$ & $\checkmark$ & $\checkmark$ & & \\
\hline $\begin{array}{c}\text { Puissanc } \\
\text { e } \\
\text { maximal } \\
\text { e }\end{array}$ & $\begin{array}{c}\checkmark \\
\text { GO }\end{array}$ & GO & $\begin{array}{c}\checkmark \\
\text { GO }\end{array}$ & $\begin{array}{c}\text { NO-GO } \\
\text { GO }\end{array}$ \\
\hline $\begin{array}{c}\text { Tension } \\
\text { d'entrée }\end{array}$ & $\begin{array}{c}\checkmark \\
\text { NO-GO }\end{array}$ & $\begin{array}{c}\checkmark \\
\text { GO }\end{array}$ & $\begin{array}{c}\text { X-GO } \\
\text { NO-GO }\end{array}$ \\
\hline
\end{tabular}

Figure 1: Morphological matrix example from design methodology course IMC156 [3]
After completing the first three assignments related to the mini-projects, the students receive the fourth assignment in which they have to use the knowledge acquired during the semester to provide a written and oral definition of their undergraduate capstone project.

At the end of the semester, the assimilation of the theoretical approaches by each student is evaluated by an exam.

\subsection{MECHANICAL ENGINEERING PROJECT I (IMC900)}

This course covers the preliminary design phase of the undergraduate capstone projects. During this course students have to evaluate the feasibility of their projects from several perspectives: safety, functionality, costs, manufacturing, assembly, and other qualitative criteria.

The weekly meetings with the professors help teams review each step of their product development process (PDP) and perform feedback on some activities upstream in the PDP.

At this point of their academic path, the students should have the requisite knowledge to carry out:

$>$ Market segmentation,

$>$ Client needs identification,

$>$ Function and specification analysis,

$>$ Bench-marking analysis,

$>$ Failure mode and effects analysis,

$>$ Quality function deployment.

In a concurrent engineering context, the control of these techniques is essential for the design of new products, processes or complex mechanical systems while respecting simultaneously several critical types of criteria (structural, economic, and qualitative) [2].

At the end of this activity, the students must have a first look at the market segmentation, the design criteria, and the project deadlines.

\subsection{MECHANICAL ENGINEERING PROJECT II (IMC916)}

The course IMC916 represents the cornerstone of the undergraduate capstone projects. During this activity, students develop skills and competencies to design a new product or mechanical system, using a concurrent engineering approach [5].

To reach the objectives of the course, students have to control several design tools, such as CAD software as well as analytical and numerical methods to pre-validate their designs.

Several concepts will be developed at this stage in accordance with all design criteria: quantitative and qualitative [6]. Afterward, the convergences of these concepts have to be performed so as to reach an 
optimum design before starting the prototyping step of the PDP.

Figure 2 illustrates the digital mockup (DMU) of four different structural concepts of an electric motorcycle developed by a multidisciplinary team of undergraduate students from both Electrical and Mechanical Engineering departments.

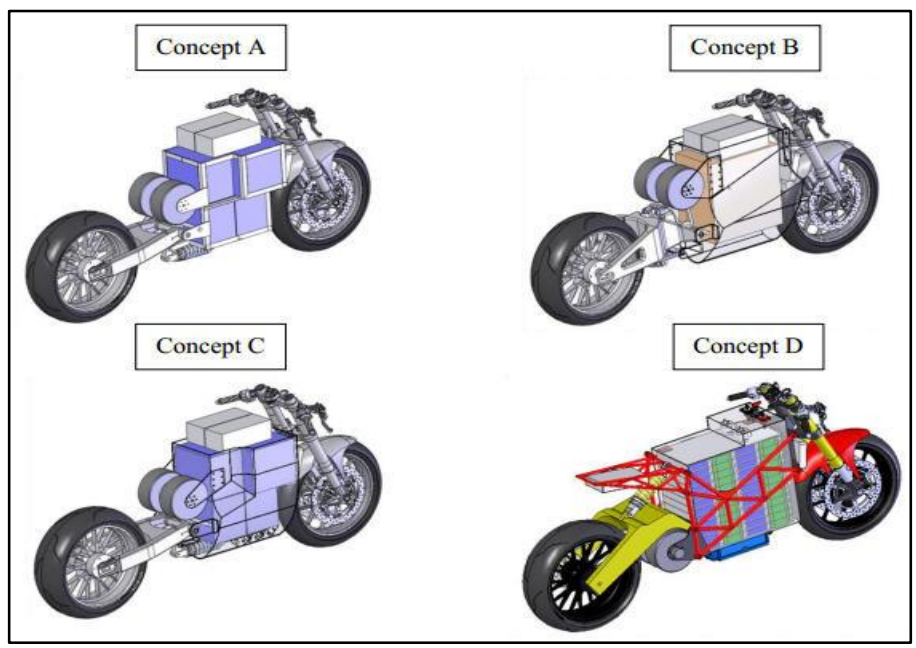

Figure 2: DMU's of an electric motorcycle [3]

The professors and/or others industrial professionals participate as advisors and evaluators during this stage of the project to ensure that the design activities are performed according to the methodology established at the beginning of the project [3 and 6].

\subsection{MECHANICAL ENGINEERING PROJECT III (IMC917)}

At this stage of the project students have acquired some knowledge and even skills regarding the process of product development, and therefore it is time to implement the theory in a functional prototype.

During their last semester, the students have the opportunity to develop their manufacturing and validation skills. The course IMC917 is dedicated to:

$>$ the manufacturing and assembly of all the components and subsystems of the prototype;

$>$ the presentation of a validation plan and its implementation;

$>$ the final evaluation of the prototype and its public exhibition.

As shown in figure 3, the physical prototyping phase of the undergraduate capstone project is one of the most exciting experiences for the students, whom are often facing a project of such scale for the first time.

At this stage of their projects, the multidisciplinary teams must manage time and budget allocated to manufacturing and validation activities [7].

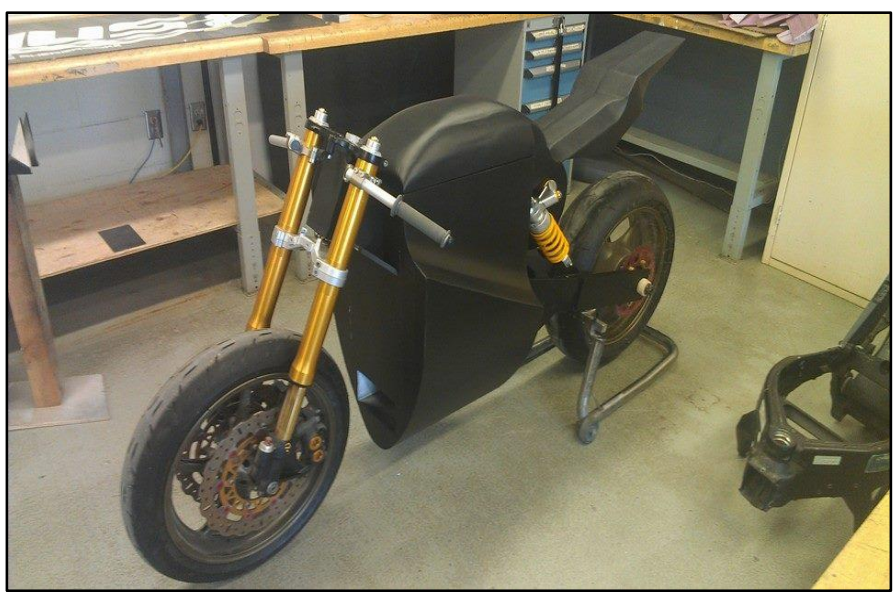

Figure 3: The physical prototype of an electric motorcycle developed at the faculty of engineering at UdeS

Major changes in the configuration of the prototype are very risky and they are not recommended at this stage of the project, because the physical and experimental validations could be compromised as a result [8 and 9]. Finally, at the end of this course, the students will have, in addition to the necessary skills to start their professional career, an invaluable background regarding the many issues linked to a project inspired from the real world of engineering design.

\section{IMPROVING MECHANICAL DESIGN COURSES AT UdeS THROUGH PROBLEM- BASED LEARNING (PBL)}

As seen in the above sections, competency based development is preferred over simple knowledge acquisition, an approach that is now well anchored into the philosophy of Universite de Sherbrooke.

However, in their undergraduate curricula, students are confronted with their first experience in terms of the product development process and they aren't yet aware about the real issues encountered in industry. Thus, the PBL experiences (such as the one briefly described in this section) inspired from industry could help students realize that all design criteria are important and the bypass of any criteria analysis step could lead to the setback of a project.

Typically there are three types of design criteria that have to be analyzed as part of the product development process of a structural component or subsystem of a vehicle:

$>$ Structural criteria ( $1^{\text {st }}$ rank, quantitative criteria);

$>$ Weight and cost criteria $\left(2^{\text {nd }}\right.$ rank, quantitative criteria);

$>$ Qualitative criteria. 


\section{A. First rank, quantitative criteria analysis}

At this step of the PDP, the engineers are interested in analyzing all criteria which have an impact on the client safety or on the product functionality (ex.: ultimate tensile, creep reliability, yield limit, etc.).

Figure 4 illustrates a generic methodology to design and validate a structural system of a recreational vehicle from a fatigue reliability perspective.

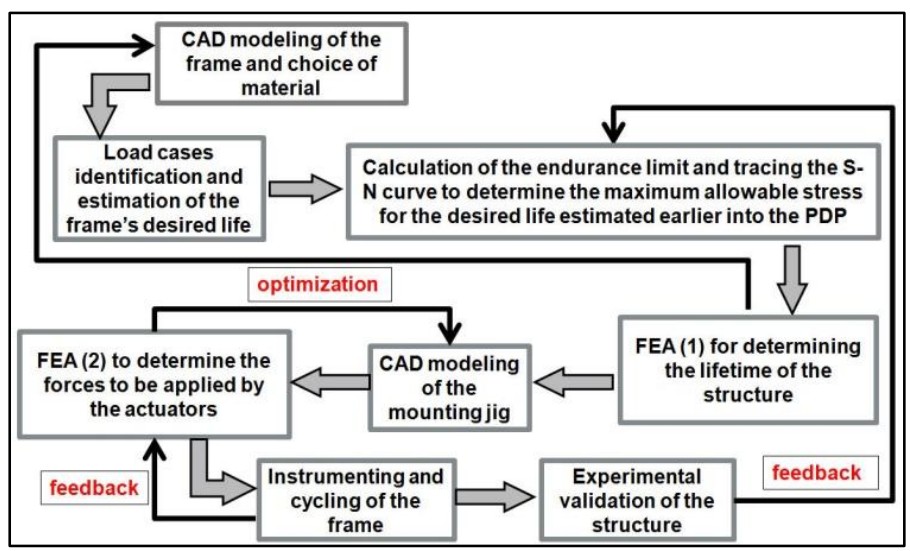

Figure 4: Design and Validation methodology for the fatigue criteria [6]

In the analysis of this type of criteria, several iterations are carried out in a numerical environment for each concept, to verify their behavior under the action of the service loads. This criterion (fatigue) has a direct impact on the vehicle functionality and also on the driver safety.

\section{B. Second rank quantitative criteria analysis}

This second step of quantitative criteria analysis is essential to verify and validate the concepts from other perspectives than those presented in the previous section. Thus, several criteria such as cost to weight ratio should be targeted and achieved by the future product, subsystem or its components.

The geometry and the material have both an incidence on the achievement of these quantitative criteria and thus, back and forth iterations must be performed to optimize the existent concepts and/or to identify new concepts.

The matrix illustrated in figure 5 allowed the team to make a decision regarding the optimum concept chosen for the prototyping stage and for the experimental tests.

For confidentiality issues, the quantitative values for the reference column are not provided.

\begin{tabular}{|c|c|c|c|c|c|}
\hline \multicolumn{2}{|c|}{ Concepts } & Reference & 1 & II & III \\
\hline \multicolumn{2}{|c|}{ Weight } & $\mathrm{X}(\mathrm{kg})$ & $-14 \%$ & $-61 \%$ & $-73 \%$ \\
\hline \multirow{3}{*}{$\begin{array}{l}\text { Raw } \\
\text { material } \\
\text { cost }\end{array}$} & Cost $/ \mathrm{m}$ & $X(\$)$ & $-27 \%$ & $+8 \%$ & $-68 \%$ \\
\hline & Meters & $X(m)$ & $-0 \%$ & $-0 \%$ & $+155 \%$ \\
\hline & Total cost & $X(\$)$ & $-27 \%$ & $+9 \%$ & $-19 \%$ \\
\hline \multirow{2}{*}{$\begin{array}{l}\text { Processes } \\
\text { cost }\end{array}$} & Folding & $X(\$)$ & $-0 \%$ & $+28,5 \%$ & $+151 \%$ \\
\hline & Welding & $X(\$)$ & $-0 \%$ & $+32,5 \%$ & $+130,5 \%$ \\
\hline \multicolumn{3}{|c|}{ Cost difference } & $-18 \%$ & $+12 \%$ & $+37 \%$ \\
\hline
\end{tabular}

Figure 5: Example of a convergence matrix from a weight/cost ratio perspective [10]

The decision regarding the optimal design was made, based on the costs that covered all the activities related to the product: assembly, manufacturing, transportation, storage, maintenance, recycling, etc.

The students should be aware that an inconclusive result for the analysis of this type of criteria could lead to a shut-down of the project or to other alternatives (shifting the manufacturing or the assembling chain, outsourcing tasks to suppliers, etc.).

\section{Qualitative criteria analysis}

In the abstract of this paper, the fatigue and the stiffness of the structural subsystem of a vehicle are presented as structural criteria and both seem to be treated on equal footage. In reality, the impact that each criterion has on the product is very different.

Indeed, the fatigue criteria has a high impact on the safety of the user and on the functionality of the vehicle, while the stiffness criteria has a high impact on the customer's perception, related to the vehicle handling. Consequently, the stiffness was rather analyzed as a qualitative criterion. Figure 6 illustrates the generic steps to be taken by engineers to design and validate a structural system of a recreational product from a stiffness perspective.

There are also several customer profiles which have to be considered when the stiffness criterion is being analyzed. Hence, after performing the market segmentation, it was found that a good majority of recreational product owners prefers a sporty behavior of their vehicles, which results in the need to have the stiffest chassis possible. 


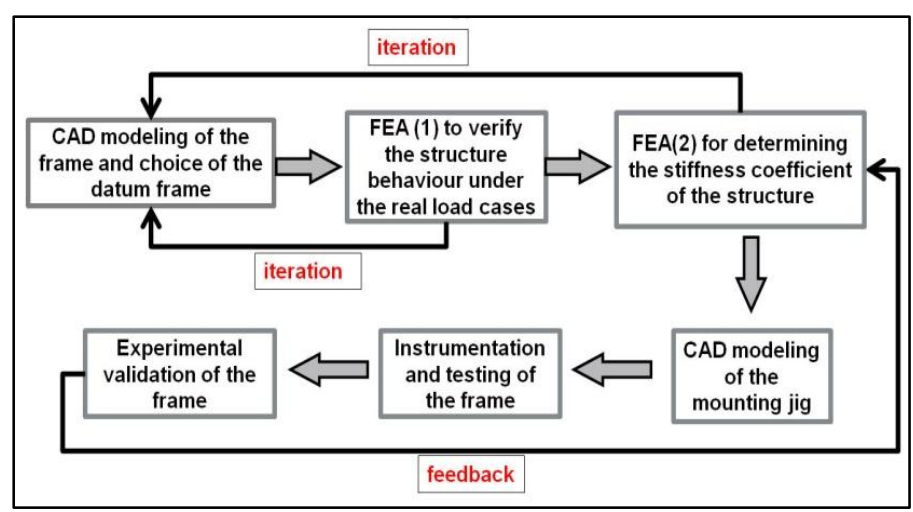

Figure 6: Design and Validation methodology with the stiffness criteria

Other qualitative criteria are explored at this step of the detailed design stage of the PDP, such as assembly, manufacturing, recycling, aesthetic, and so on.

Again, the students should be aware that in the "real world", a project could be stopped if the product does not respect all the design criteria which in turn are the reflection of the client needs.

The point that should be emphasized is that all criteria are very important for the success of the product; the only difference between the three categories (see sections A, $\mathrm{B}$, and $\mathrm{C}$ ) would be their prioritization.

\section{Prototyping phase}

From the fatigue stand point, the second finite element simulation (FEA2) shown in Figure 6, serves to identify the validation parameters (actuator forces, clamping points, etc.).

As shown in Figure 7, a digital mockup (DMU) of the structure fixed on the mounting jig was performed in the CATIA environment and then modeled in the ANSYS environment in order to simulate the structure behavior on the fatigue testing machine.

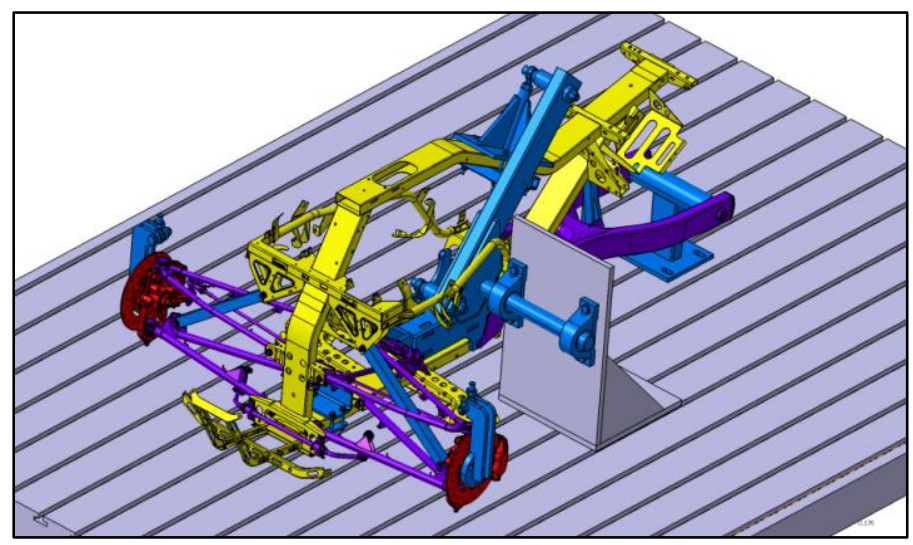

Figure 7: The DMU of the assembly on the testing machine
As shown in Figures 4 and 6 the jig configuration was established after several back and forth iterations at the second simulation step (FEA2).

Following the verification of all design criteria, the team is allowed to start the fabrication of the physical prototype. Figure 8 illustrates the structural system of a recreational product, instrumented and ready for the experimental tests.

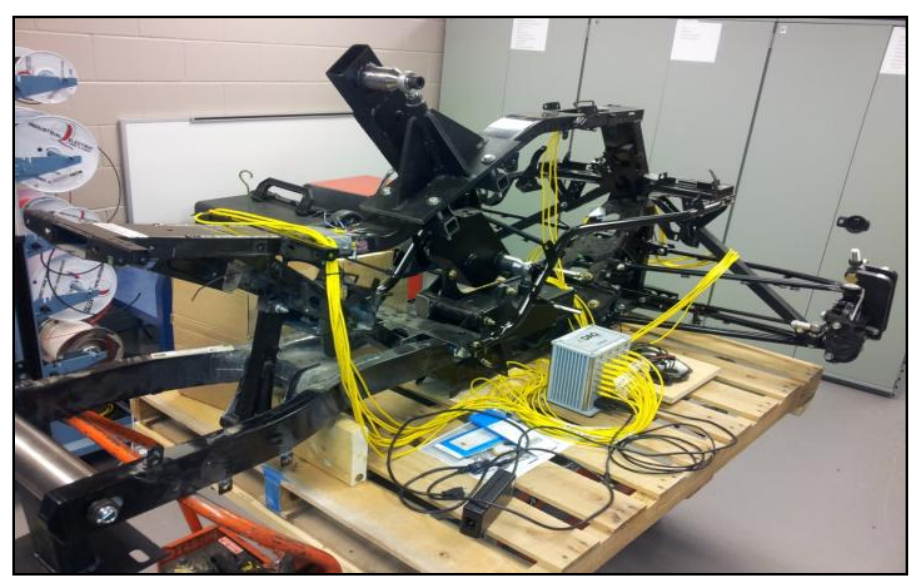

Figure 8: Instrumented physical prototype, before its installation on the testing machine

The e-DAQ acquisition system was employed to record the values of several validation parameters such as strain, stress, displacement and forces.

To manage the recording of all required data and to monitor the behavior of the structure during the experimental test, two dedicated software were used: TCE_v3.15 and EASE 3.

\section{E. Experimental validation}

Generally, the experimental stage of the PDP should cover all the necessary tests in order to verify and validate the structural criteria of a concept. Thus, the fatigue test is performed to validate the product or the subsystem under conditions which are similar to the actual load cases, while the stiffness test is performed to validate the results of the numerical calculations provided earlier in the PDP.

However, the driving feeling and handling of the vehicle are qualitative criteria that will be validated only after a road test. The stiffness represents just a design parameter that influences these qualitative criteria.

The experimental tests (fatigue and stiffness) have therefore proven the theory that all design criteria (quantitative and qualitative) should be seen as having the same magnitude of importance so that only their prioritization within the PDP is different. 


\section{CONCLUSIONS}

The authors of this paper have studied the possibility of optimizing the design course in Mechanical Engineering at Université de Sherbrooke, by integrating into the existing development process, two generic methodologies applicable in both the automotive and recreational products industries.

The integration of problem-based learning earlier into the engineering design course curriculum provides students competencies in addition to a realistic point of view regarding the product development process.

Moreover, the design and validation methodologies proposed in the above section, provide useful guidelines for project planning by strategically allocating resources needed at the different stages of a project.

The gap identified between the load cases identification stage and the experimental validation stage is fulfilled by the imposition of two finite element analyses (FEA1 and FEA2) which allow a better correlation between the results of each corresponding step of the PDP.

The integration of the proposed generic methodologies in the Mechanical Engineering Department curricula at Université de Sherbrooke, encourages students to consider all the design criteria constraining a product and to make sound decisions regarding the issues encountered in both undergraduate and graduate design projects.

\section{Acknowledgements:}

The theoretical and experimental approaches described in this paper were supported by a grant from the Automotive Partnership Canada and the Natural Sciences and Engineering Research Council of Canada.

\section{REFERENCES}

1. Otto K. et Wood K. (2001), Product Design, New Jersey: Prentice Hall.

2. Cooper G. Robert (1993), Wining at New Products. Accelerating the process from Ideea to Launch, Cambridge Massachusetts: Perseus Books.

3. Denis Proulx, François Charon et Patrick Doucet (2002), IMC156-Notes de cours, Université de Sherbrooke, Dépertement de genie mécanique.

4. Juvinall C. R., Marshek M. C., (2012), Fundamentals of Machine Component Design ( $5^{\text {th }}$ edition), John Wiley \& Sons, Inc., ISBN: 9781118012895 (2012).

5. Boothroyd G., (2002), Product Design for Manufacture and Assembly $2^{\text {nd }} \mathrm{ed}$. rev. and expanded, New York: Marcel Dekker.
6. Iorga C. and Desrochers A., (2013), Design and Validation Methodology applied to a roadster frame based on life prediction, Canadian Engineering Education Association Conference (CEEA 2013), Montréal, QC, June 17-20, 2013.

7. Mogenot Y., (2013), Strategie d'optimisation des procédés d'assemblage et de fabrication dans le processus de reduction de poids du chassis d'un véhicule roadster - mémoire de maîtrise, Université de Sherbrooke.

8. Kuo T-C, Huang SH, Zhang SH, (2001), Design for Manufacture and Design for X: Conceps, Applications and Perspectives, Computers and Industrial Engineering 41 (3): 241-260.

9. Maropoulos P.G., Ceglarek D., (2010), Design verification and validation in product lifecycle, CIRP, Annals-Manufacturing Technology 59.

10. Iorga C., Desrochers A., (2014), Design \& Validation Methodology from a Life Prediction Perspective for the Structural Components of a Recreational Product, European Scientific Journal (ESJ), vol.10, no.6, ISSN:1857-7881, p. 359-377. 